\title{
Long-term Site Fidelity and Individual Home Range Shifts in Lophocebus albigena
}

\author{
Karline R. L. Janmaat • William Olupot • \\ Rebecca L. Chancellor • Malgorzata E. Arlet • \\ Peter M. Waser
}

Received: 30 November 2008 / Accepted: 28 December 2008 /

Published online: 10 March 2009

(C) The Author(s) 2009. This article is published with open access at Springerlink.com

\begin{abstract}
We investigated long-term site fidelity of gray-cheeked mangabey (Lophocebus albigena) groups in Kibale National Park, Uganda. Concurrently, we monitored shifts in home range by individual females and subadult and adult males. We documented home range stability by calculating the area of overlap in successive years, and by recording the drift of each group's monthly centroid from its initial location. Home ranges remained stable for 3 of our 4 groups (overlap over $10 \mathrm{yr}>60 \%$ ). Core areas were more labile, but group centroids drifted an average of only $530 \mathrm{~m}$ over the entire decade. Deviations from site fidelity were associated with dispersal or group fission. During natal dispersal, subadult males expanded their home ranges over many months, settling $\leq 4$ home ranges away. Adult males, in contrast, typically dispersed within a few days to an adjacent group in an area of home range overlap. Adult males made solitary forays, but nearly always into areas used by their current group or by a group to which they had previously belonged. After secondary dispersal, they expanded their ranging in the company of their new group, apparently without prior solitary exploration of the new area. Some females also participated in home range shifts. Females shifted home ranges only within social groups, in association with temporary or permanent group splits. Our observations raise the possibility that male mangabeys use a finder-joiner mechanism when moving into new home ranges during secondary dispersal.
\end{abstract}

K. R. L. Janmaat

Department of Primatology, Max Planck Institute for Evolutionary Anthropology, Deutzerplatz 6, 04103 Leipzig, Germany

W. Olupot

Wildlife Conservation Society, P.O. Box 7487, Kampala, Uganda

R. L. Chancellor - M. E. Arlet

Department of Anthropology, University of California, Davis, CA 95616, USA

P. M. Waser $(\bowtie)$

Department of Biological Sciences, Purdue University, West Lafayette, IN 47907, USA

e-mail: pwaser@bilbo.bio.purdue.edu 
Similarly, females might learn new resource locations from male immigrants before or during group fission.

Keywords dispersal - group fission - Kibale National Park · mangabey · spatial memory

\section{Introduction}

Site fidelity, the tendency to stay or return to a previously occupied location, occurs in numerous species belonging to a variety of taxa, including insects, birds, mammals, reptiles, and amphibians (Baird et al. 2008; Gamble et al. 2007; Krebs 1970; Newton 1993; Switzer 1997; Schjorring et al. 2000; Wauters et al. 1995; Webb and Shine 1997; Young et al. 2006). Primates, even those that are not territorial, are widely presumed to be site-faithful. A few primate field studies have continued long enough to document site fidelity over many years and even across generations. For example, Jolly and Pride (1999) and Mertl-Millhollen (2000) observed ring-tailed lemur troops (Lemur catta) using the same sleeping sites and core areas over a period of 33 yr. Individual male chimpanzees (Pan troglodytes) remain faithful to areas used by their mothers even after the mother has died (Murray et al. 2008).

Many advantages of long-term site fidelity could be imagined. An intuitive possibility is that site fidelity simply reflects stability in the location of important resources. However, the hypothesis is not universally supported; primates sometimes exhibit site fidelity even when prime feeding locations change. For example, a case study of a deposed $\alpha$-chimpanzee male found that he tended to remain in the same area despite changes in his dominance status and the potential to move into areas with higher fruit availability (Murray et al. 2008). Similarly, female orangutans (Pongo pygmaeus) remained in the same home range throughout a period of mast fruiting, even though neighboring areas produced more fruit (Singleton and van Schaik 2001). An extreme case is that of a group of Nilgiri langurs (Presbytis johnii) that vacated their original home range only when the last trees were cut (Poirier 1968).

Cases like these suggest the importance of spatial information per se. Individuals might gain foraging or safety advantages when they stay in familiar areas by knowing the location of efficient travel routes, high-quality food sources, or safe escape routes. Indeed, movements into new areas are known to increase predation and travel costs in vervets (Cercopithecus aethiops) and gray-cheeked mangabeys (Lophocebus albigena) respectively (Isbell et al. 1990; Janmaat and Chancellor 2008). Travel routes in spider monkeys (Ateles belzebuth) and woolly monkeys (Lagothrix poeppigii) are stable across years, consistent with the possibility that monkeys remember nodes or intersections connected by relatively safe and energetically efficient arboreal pathways (Di Fiore and Suarez 2007).

Despite the potential advantages of long-term site fidelity, primates do sometimes shift home ranges. For example, baboons (Papio cynocephalus) and vervets can shift group home ranges abruptly in response to sudden declines in habitat quality and vegetation composition (Altmann and Alberts 2003; Bronikowski and Altmann 1996; Isbell et al. 1990). Mountain gorilla (Gorilla gorilla) groups sometimes shift their home range in response to severe mate competition (Watts 1998). Home range shifts 
often follow group fission: red-tail monkeys (Cercopithecus ascanius: Struhsaker and Leland 1988), blue monkeys (C. mitis: Cords and Rowell 1986), Japanese macaques (Macaca fuscata: Sugiyama 1960), rhesus macaques (M. mulatta: Chepko-Sade and Sade 1979). At an individual level, many primates also shift ranges during natal or secondary dispersal, e.g., baboons (Alberts and Altmann 1995), macaques (van Noordwijk and van Schaik 2001), and vervets (Cheney and Seyfarth 1983).

We investigated site fidelity of gray-cheeked mangabey (Lophocebus albigena johnstoni) groups and individuals in Kibale National Park, Uganda over 10 yr. Early researchers found that over the short term, Kibale mangabeys occupied large and highly overlapping home ranges with no sign of site-specific or territorial defense (Waser 1976, 1977). Mangabeys are largely frugivorous, and the spatial and temporal distribution of fruiting by important food species is highly variable (Chapman et al. 1997, 1999; Olupot 1998; Struhsaker 1997; Waser 1975). Waser described mangabeys as seminomadic, continuously and erratically shifting over several square kilometers of forest in response to temporary food superabundances. He speculated that home ranges might be limited primarily by a tendency to return to familiar areas after occasional encounters with neighboring groups (Waser 1976; cf. Barrett and Lowen 1998; Hutchinson and Waser 2007). But extreme spatiotemporal variability in the location of fruit bearing trees might be exactly the ecological situation that would make knowledge of resource locations, and thus site fidelity, especially advantageous. In fact, recent studies showed that gray-cheeked mangabeys rely on spatiotemporal knowledge of particular fruit bearing trees in their foraging efforts (Janmaat et al. 2006a, b).

To assess whether the apparent lack of site fidelity exhibited by mangabeys over the short term (months) persists over the long term (years to decades), we took advantage of a set of males that Olupot radiocollared in the late 1990s. Olupot collared all adult and many subadult males in a $c a .25 \mathrm{~km}^{2}$ area near the Makerere University Biological Field Station, Kanyawara. Radios allowed continuous monitoring of male locations during 1996-2000. Distinctively colored collars have ensured reliable identification of these males and their associated groups even after the radios ceased transmitting. Here, we combine spatial data from our separate studies to address the following questions:

1) How stable are the home ranges of 4 social groups that have been followed from 1996 to 2006 ?

2) Under what conditions do groups or individuals enter new areas? How do these conditions differ for males and females? How often do home range shifts occur, and what is their magnitude?

3) What do spatial ranging data from long-term radiotracking of animals that shift their home ranges tell us about how mangabeys might acquire spatial information?

\section{Methods}

Study Area and Data Collection

The Kanyawara study area is a mosaic of primary and regenerating medium-altitude moist evergreen forest adjacent to the Makerere University Biological Field Station in Kibale National Park, Uganda (Chapman et al. 1997; Olupot et al. 1994; Struhsaker 1997;). An extensive trail system allows ready access to forest $\leq 5 \mathrm{~km}$ 
from the field station $\left(0^{\circ} 34^{\prime} \mathrm{N}, 30^{\circ} 22^{\prime} \mathrm{E}\right)$. Beginning in 1996 , Olupot and a team of 3 field assistants systematically located all 7 mangabey groups in this area (ca. $25 \mathrm{~km}^{2}$ ); once groups were habituated, he began a program of radiocollaring males. Olupot darted and collared all adult and most subadult males in each group during 1996-1997; he collared immigrants entering groups during 1996-1998 as they arrived(Olupot 2000a, b). All males with functional transmitters were visually located 2-3 times per week over this period, and at least once a week through 2000. Males whose transmitters ceased functioning were located at least once a month.

Each time a male was located, Olupot recorded its location using either a trail map or GPS, and noted the identity of and distance to any other mangabeys $\leq 200 \mathrm{~m}$. He also determined the demographic structure of each group through opportunistic counts when groups crossed canopy gaps. Like most Papionini, groups of Lophocebus appear to be matrilines with several associated adult males; we can reconstruct the movement of each group from the locations of males that were recorded as being $\leq 50 \mathrm{~m}$ of the females in that group. Olupot followed males in 7 groups, but here we focus on 4 groups that Olupot denoted Butanzi 1 (BU1), Mikana A (MKA), Lower Camp (LC), and CC.

Between 1997 and 2000, this approach allowed Olupot to locate each group on an average of 21.2 times/mo, with observations spread evenly across the year. In 20012003, Olupot's field assistants continued to locate the groups monthly, and Arlet (January-June 2001) and Chancellor (July-September 2002) began pilot studies that included these same 4 groups. Only a few females were individually recognizable during this period, but groups remained unambiguously distinguishable. Age-sex structure, and specifically the number of adult females, differed consistently between groups; also, groups contain multiple males that do not disperse simultaneously and on average only once every 2 yr (Olupot and Waser 2005), providing a check on group identity as determined from age-sex structure and the few recognizable females.

In 2003, Chancellor and Janmaat renewed intensive following of all 4 of these groups, locating group centers by GPS every half-hour during an average of $7 \mathrm{~d}$ each month (Chancellor and Isbell 2008; Janmaat 2006; Janmaat et al. 2006a). By this time, the groups were very well habituated, allowing approach distances of 2-10 m; Chancellor and Janmaat were able to recognize most males and all adult females individually. These studies continued through 2005. During 2006, Arlet continued to follow the same groups, now easily identifiable because most adults were individually recognizable, locating the trail intersection nearest each group's center at $c a$. 1-h intervals on an average of $6 \mathrm{~d} / \mathrm{mo}$.

\section{Home Range Stability Measurements}

We converted all locations to universal transverse Mercator (UTM) coordinates using the map constructed by A. Houle (Pontzer and Houle 2005). Because different investigators recorded locations in different ways, we cannot compare fine details of ranging patterns, but we can document group home range stability in 2 ways.

First, we used the Home Range Extension for ArcView ${ }^{\circledR} 3.1$ (Rodgers et al. 2007) to estimate kernel home ranges for each group in each year. Probability kernels are regions around each point location containing some likelihood that the group is present; the width of the kernel is based on a smoothing parameter (Kernohan et al. 
2001; Mitchell 2006). We chose the fixed-kernel method with the smoothing parameter selected by least-squares cross-validation (LCSV) because this approach generally produces the most accurate and precise estimates (Kernohan et al. 2001; Powell 2000; Seaman et al. 1999). We used the 50\% and 95\% contours, respectively, as indications of each group's annual core area and home range boundaries. As indices of temporal home range stability from one year to the next, we calculated the area of overlap between $50 \%$ and $95 \%$ contours from successive years (Fieberg and Kochanny 2005). As a longer-term indicator of stability, we calculated the overlap between 50\% and 95\% contours observed in 1997 with those observed in 2006 . We obtained temporal overlap values using the Minta index (Minta 1992):

$$
\text { Percent overlap }=\frac{((\text { area } \mathrm{A}) \cap(\text { area } \mathrm{B}))}{\sqrt{(\text { area } \mathrm{A} * \text { area } \mathrm{B})}} * 100
$$

where areas A and B represent the home ranges used by the same group in 2 different years, and the numerator represents the overlap between areas A and B calculated in ArcView 3.1 via Xtools.

Second, we calculated each group's monthly centroid, the center of all its locations during that month (Kernohan et al. 2001). We then plotted the rate at which each group's monthly centroid moved away from its location at the beginning of the study, which we term centroid drift. If a group's use of space were identical from one month to the next, centroid drift would be 0 ; if it showed no site attachment at all, its monthly centroid would continue to drift away from its initial location throughout the study.

We also investigated shifts in range use by individuals. Male mangabeys are sometimes only loosely associated with groups and can remain solitary for many months (Olupot and Waser 2005). We reconstructed ranging patterns for males by plotting successive radiolocations through time, including locations when those males were alone or visiting groups other than their own. Our sample of tracks for individual males includes 5 subadults and 30 adults followed during 1997-2000.

Females form the spatial core of the group and individual females are found, on average, $<25 \mathrm{~m}$ from the group's center (Chancellor and Isbell 2008; Waser 1985). Early in the study, because only a few females were individually recognizable, we could not exclude the possibility of female movement between groups. However, Chancellor, Janmaat, Arlet, and field assistants were able to distinguish all females during 2004-2006 and no females dispersed during this period. Within the limits of our data, each female's home range use therefore tracked that of her group.

Where available, we used opportunistic field notes on the interactions and location of identifiable individuals during home range shifts to supplement data from radio and GPS locations.

\section{Results}

Site Fidelity of Social Groups: Home Range and Core Area Overlap

Figure 1 shows the succession of annual home ranges for all study groups. Across groups and years, home range overlap from one year to the next averaged $78 \%$ (Table I). Over the entire decade 1997-2006, home ranges remained very 


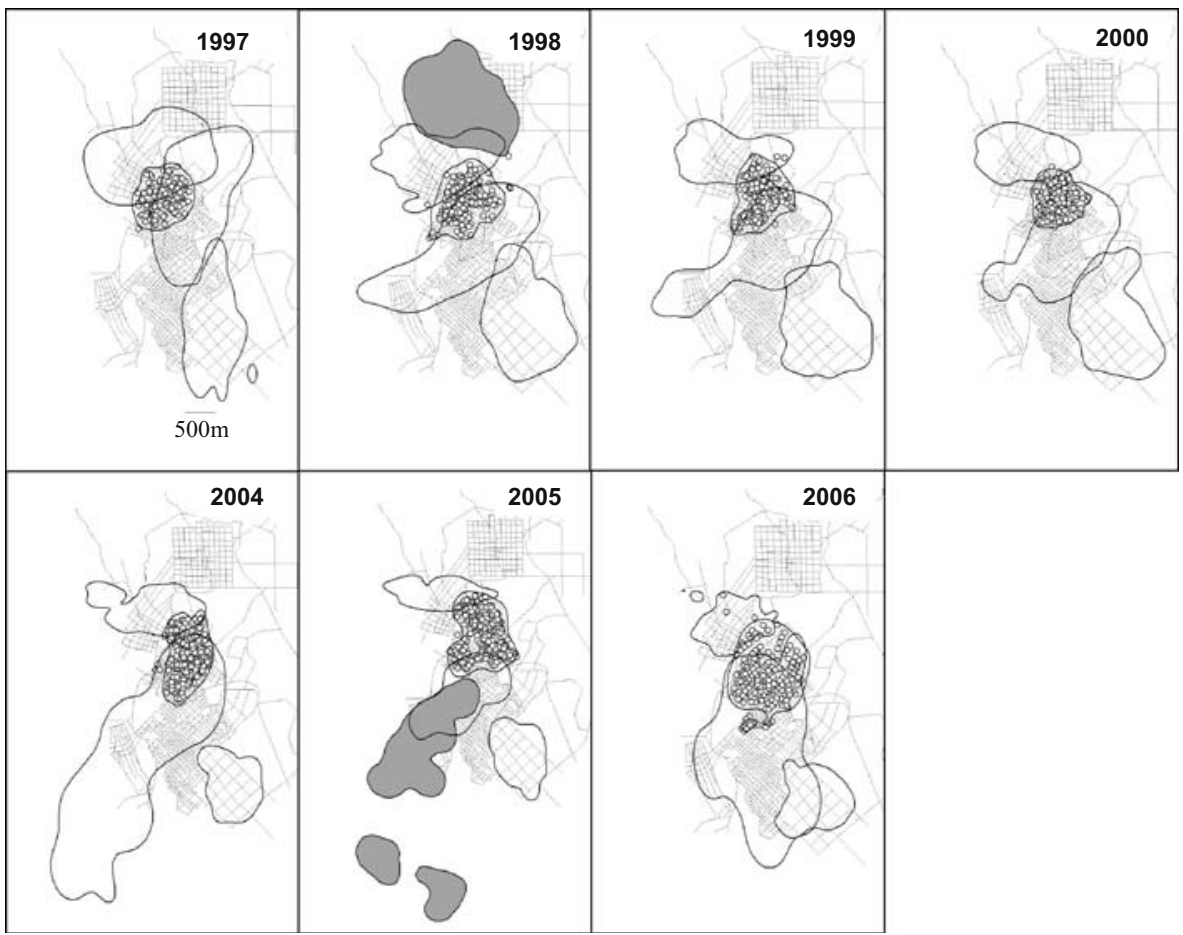

Fig. 1 Succession of annual home range boundaries (95\% kernels) of the 4 focal groups and two postfission daughter groups (shaded ranges). From top to bottom, home ranges are of the MKA, LC, BUI, and CC groups; shaded home ranges in 1998 and 2005 are those of MKB and BU2, respectively. Circles illustrate the relationship between kernels and the raw locational data. In this case, the locational data are for the LC group. Home range sizes average $c a$. 250 ha.

similar for 3 of the 4 groups (10-yr overlap $>60 \%$ ). The home range of the fourth group, BU1, was more labile, with a 10 -yr overlap of only $38 \%$ (Table I).

Core areas were also quite stable from one year to the next; core area overlap between successive years averaged $60 \%$ (Table I; Fig. 2). However, over the long term, core area stability varied among groups. Two groups' core areas were relatively fixed (MKA, CC: 10 -yr overlap $>50 \%$ ), the LC group's core area appeared to oscillate around a stable nucleus, but BU1's core area shifted repeatedly and the 10 -yr overlap was only $4 \%$ (Table I; Fig. 2).

The relative stability of home ranges and most core areas over $10 \mathrm{yr}$ is especially striking given the fact that 4 group fissions occurred during this period. In 1997, MKA spun off a daughter group (MKB) but the remaining individuals continued to use the original home range and core area. In 2004, after a substantial home range expansion, BU1 split into 1 daughter group (BU2) that used a largely new home range and another that then retracted its range to the area it had used during 1999 and 2000 (Fig. 1). The CC group fissioned between 2002 and 2004, when observers were not present. During that same time period, a small new group appeared in the area of overlap between the MKA and LC home ranges. No individuals in the new group were recognizable, but their degree of habituation indicated that they must have split from MKA or LC. 
Table I Temporal stability of core areas and home ranges as measured by percentage overlap (Minta index) between areas used by the same group in successive years or between 1997 and 2006

\begin{tabular}{|c|c|c|c|c|c|c|c|c|c|}
\hline \multirow[b]{2}{*}{ Area } & \multirow[b]{2}{*}{ Group } & \multicolumn{7}{|c|}{ Overlap between successive years } & \multirow{2}{*}{$\begin{array}{l}\text { Overlap across } \\
10 \text { years }\end{array}$} \\
\hline & & $\begin{array}{l}1997- \\
1998\end{array}$ & $\begin{array}{l}1998- \\
1999\end{array}$ & $\begin{array}{l}1999- \\
2000\end{array}$ & $\begin{array}{l}2003- \\
2004\end{array}$ & $\begin{array}{l}2004 \\
2005\end{array}$ & $\begin{array}{l}2005- \\
2006\end{array}$ & Mean & \\
\hline \multirow{4}{*}{$\begin{array}{l}\text { Core area } \\
(50 \% \text { kernel })\end{array}$} & MKA & 74 & 75 & 85 & & 39 & 53 & 65 & 52 \\
\hline & $\mathrm{LC}$ & 70 & 75 & 59 & & 46 & 40 & 58 & 21 \\
\hline & $\mathrm{CC}$ & 43 & 84 & 69 & & 31 & 43 & 54 & 52 \\
\hline & BU1 & 69 & 76 & 80 & 63 & 53 & 26 & 61 & 4 \\
\hline \multirow{4}{*}{$\begin{array}{l}\text { Home range } \\
(95 \% \text { kernel })\end{array}$} & MKA & 82 & 83 & 88 & & 79 & 60 & 78 & 63 \\
\hline & $\mathrm{LC}$ & 82 & 89 & 83 & & 77 & 84 & 83 & 67 \\
\hline & $\mathrm{CC}$ & 70 & 86 & 86 & & 87 & 81 & 82 & 66 \\
\hline & BU1 & 54 & 84 & 83 & 76 & 54 & 61 & 69 & 38 \\
\hline
\end{tabular}

Site Fidelity of Social Groups: Centroid Drift

Group centers of activity changed considerably on a short time scale. After just $1 \mathrm{mo}$, the average group's monthly centroid was $220 \mathrm{~m}$ from its initial location (Fig. 3). This distance increased slowly through time. However, home range centers

Fig. 2 Stability of annual core areas. The thick black, medium gray, and thin black lines represent the contours from 1997 , 2006, and the intervening years, respectively.

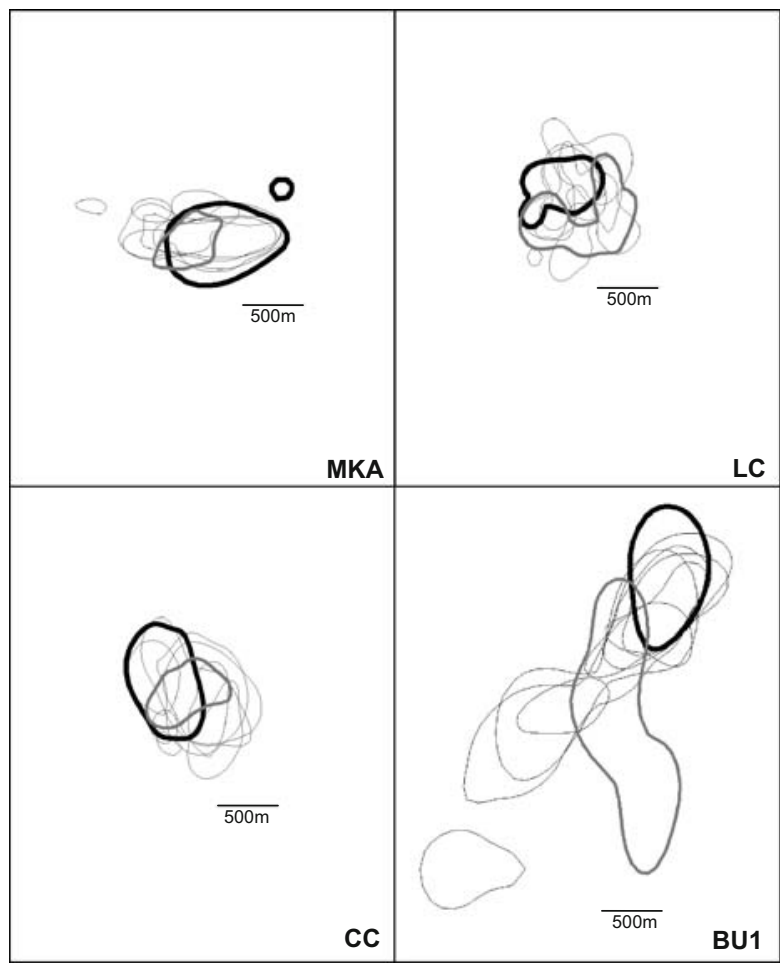


Fig. 3 Stability of the monthly centroid of group activities. Each group's centroid drifts away from its initial location during the 6 mo after observations begin, but then moves no farther (mean $\pm \mathrm{SE}, N=4$ groups).

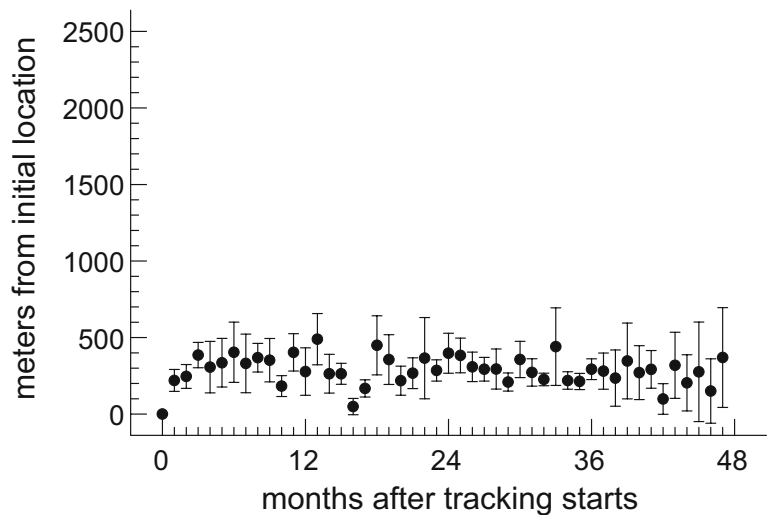

did not drift indefinitely. Instead, the drift distance approached an asymptote after ca. $6 \mathrm{mo}$, at which point the center of a group's activity had moved $c a .400 \mathrm{~m}$ from its initial location. In other words, it took ca. 6 mo for a group to visit all of the areas it normally used, but on a longer time scale each group tended to revisit basically the same areas. After $4 \mathrm{yr}$ of observation, the monthly centroid was on average $370 \mathrm{~m}$ from its original location; after $10 \mathrm{yr}$, the mean drift distance was $530 \mathrm{~m}$. As noted in our analysis of core area stability, the BU1 group's range was substantially more labile than those of the other 3 groups; its centroid moved $1050 \mathrm{~m}$ over $10 \mathrm{yr}$.

\section{Individual Range Shifts by Males: Natal Dispersal}

As old juveniles and subadults, young male mangabeys gradually became peripheralized, spending more and more time alone or visiting nearby groups (Olupot and Waser 2005). Collared subadult males emigrated around the time they reached adulthood - marked by their first "whoopgobble" call- and spent 2-18 mo as solitaries before immigrating into another group. During this period of isolation, each young male left not only his natal group, but also his natal home range. While solitary, the 5 collared subadults made forays into the home ranges of $\leq 4$ other groups, gradually moving into areas never used by their natal groups.

After leaving the home range of his natal group, each young male was usually alone, but sometimes visited other groups for periods of a few hours up to a few days. Young males also made occasional brief return visits to their natal home range and group. The track of the male for which our data were most complete is illustrated in Fig. 4. Four of 5 young males immigrated into groups whose home ranges were not contiguous with that of their natal group.

We calculated the monthly centroid of each collared male's locations, producing a movement index for individual males corresponding to group centroid drift. During the initial few months of tracking, subadult male centroid drift resembled that of entire social groups, but after a year, their centers of activity had moved $750 \mathrm{~m}$ from their initial locations (Fig. 5). After $36 \mathrm{mo}$, the average young male was $1450 \mathrm{~m}$ (range 200-4900 m) from his initial location. Individual variation was considerable; 1 subadult moved $5500 \mathrm{~m}$ from his initial location before contact was lost. 


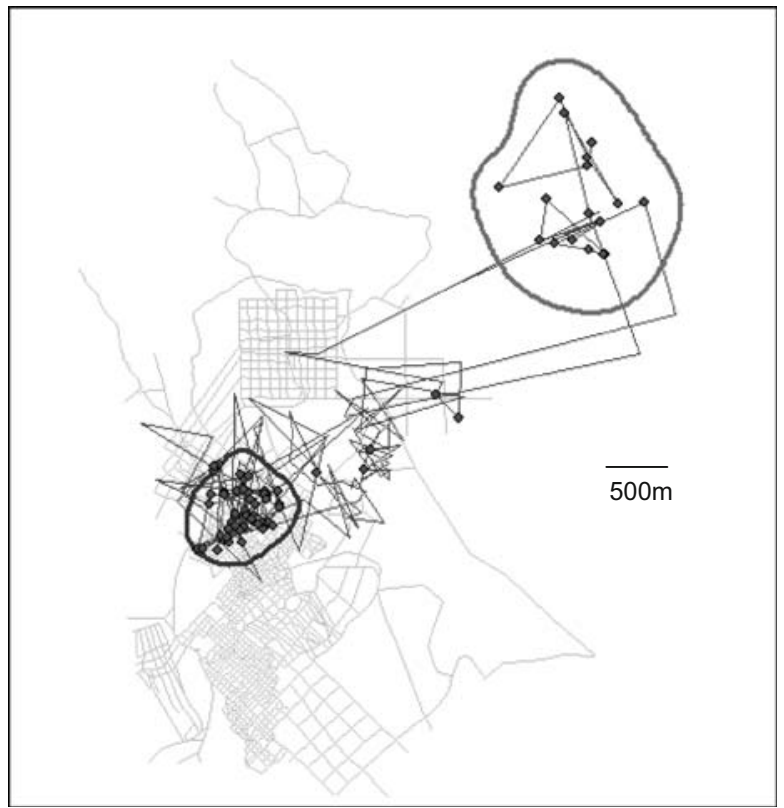

Fig. 4 Movement by subadult male RB over 36 mo including natal dispersal (here and elsewhere, we define dispersal as a movement that concludes with long-term residence, including reproductive activity, in a new group; Olupot and Waser 2005). The male detached himself from his presumed natal group (LC) after $c a$. 6 mo of observation, initially making forays outside the LC group's range but returning occasionally to it, then drifting through the ranges of several other groups before finally joining the NE group, almost $4 \mathrm{~km}$ away, 11 mo later. LC group's home range (95\% kernel) while RB was in it is in the lower left; NE group's range is in the upper right. The line links all sightings of RB in temporal order; circles denote sightings in a social group (otherwise he was solitary).

\section{Individual Range Shifts by Males: Secondary Dispersal}

Most of the 30 males collared as adults confined their movements to the same home range as did females in the group they were associated with. This was true even though adult males often ranged hundreds of meters away from the females in their

Fig. 5 Drift through time of the monthly centroids for 5 males initially collared as subadults (mean $\pm \mathrm{SE}$ ). For the first $6 \mathrm{mo}$, subadult male movements resemble those of their natal group, but young males then drift away to varying degrees. Most of these males were not collared until 1998, so that we have systematic location data for 3 yr only.

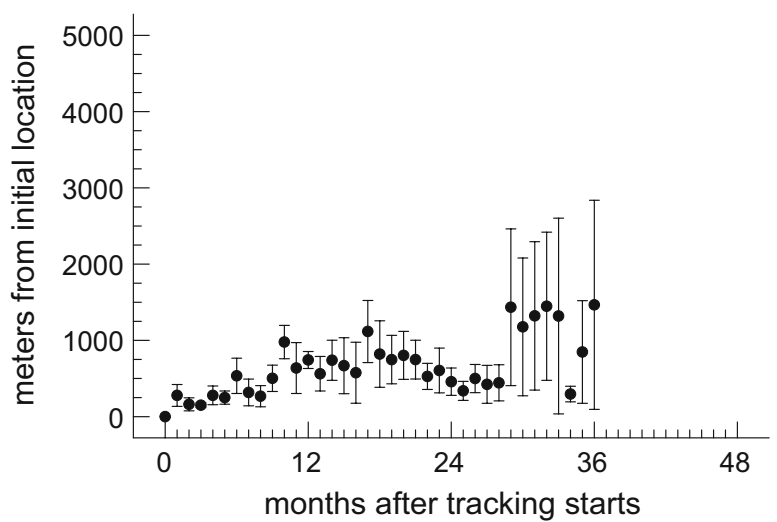


group. By sometimes moving independently of females, adult males visited a larger subset of their home range each month, but they did not use a larger home range.

However, most of these males subsequently dispersed once or more (Olupot and Waser 2005), each time shifting to a largely new home range. A few of the range shifts by males first captured as adults ( 3 of the 15 that we tracked in detail) resembled those of subadult males in involving extensive solitary exploration far outside the home range of the group where we initially captured the male. For example, male MR was radiocollared as a member of the MKA group, but soon drifted away, beginning a solitary period of 11 mo during which he gradually expanded his range beyond that of MKA through the home ranges of LC and BU1 (Fig. 1). He eventually joined the UC group, south of BU1, but he twice left it for a week or more to revisit parts of his former range.

However, the pattern of home range shift during most (12/15) presumed cases of secondary dispersal was quite different from that observed during natal dispersal. Secondary dispersal was usually quick, with a median duration of $6.5 \mathrm{~d}$, and to an immediately adjacent group. Unlike young males, these adult males did not make forays into unfamiliar areas before dispersal. Instead, their first sightings after secondary dispersal were either in an area of overlap between the old and new groups (9 times), or outside the range of the old group, but in an area that the male had used earlier in his life (3 times). After dispersing, adult males immediately adopted their new group's entire home range, apparently without having explored the nonoverlapping area independently.

Figure 6 illustrates these patterns with the track of a single male that dispersed repeatedly during the study. In each case, immigration into a new group was associated with a rapid and complete shift of home range. After each successive case of immigration, this male occasionally left his new group and revisited parts of his earlier home range. In no case, however, did we detect any exploration of his new group's home range before he actually dispersed.

Secondary dispersal, though often short in distance, can result in substantial cumulative displacement over a male's lifetime (Fig. 7). Centroid drift for adult males averaged $1150 \mathrm{~m}$ (range $100-4550 \mathrm{~m}$ ) during the 36 mo after capture. By 2006 , the 5 collared males that were still within the 4 study groups had moved between $470 \mathrm{~m}$ and $2260 \mathrm{~m}$, but other males left the study area entirely; the longest move by an adult male before his radiocollar ceased operation was $4700 \mathrm{~m}$. We tracked males originally collared near Kanyawara to locations scattered across a significant proportion of the Kibale Forest (Fig. 8).

\section{Individual Range Shifts by Females After Group Fission}

Female mangabeys do not shift home ranges by dispersing individually, but they may move into new areas during group fission. The MKA group (first followed in June 1996) contained 6 adult females and $\leq 8$ adult males during the 6 mo preceding its fission in July 1997. MKA usually foraged as a single group during this period, but it split into 2 subgroups for several days during May 1997 and then repeatedly during July. One of these 2 subgroups (MKB) contained 3 females, a juvenile, an adult male that had immigrated in February from an unknown location, and adult male OG. On August 1, these individuals moved several hundred meters outside of 

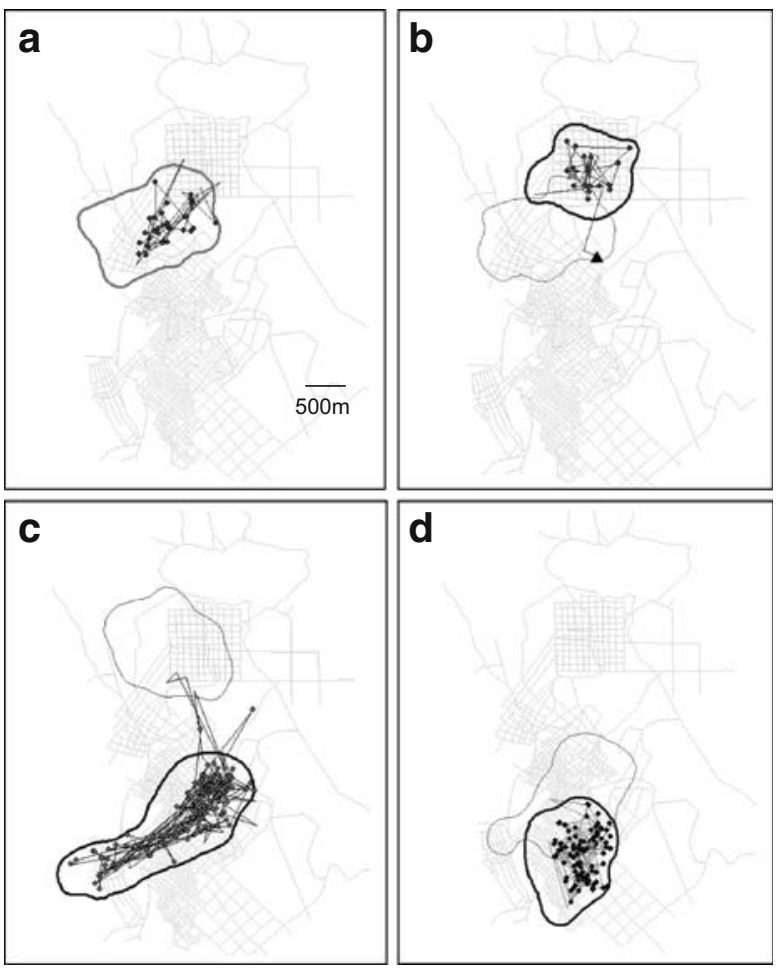

Fig. 6 Successive home range shifts by adult male OG, 1996-1999, as an example of movement by a male that repeatedly engaged in secondary dispersal. In each panel, the home range (95\% kernel) of OG's current group has a dark outline; the range of his previous group during the same period is light. As in Fig. 4, locations are marked with a circle when OG was in a social group; during other sightings, he was alone. (a) From November 1996 to July 1997, OG was a member of the MKA group, but tended to use the eastern part of its range and was sighted alone during 2 forays outside MKA's range to the northeast. (b) From August to November 1997, OG was 1 of 6 individuals that left MKA to form the MKB group, which immediately established a new range to the northeast of MKA. In November 1997, OG drifted away from MKB into the area he had previously used with MKA. (c) In December 1997, he encountered and joined the BU1 group just outside the area he had used when he was with MKA. He then shifted his ranging pattern dramatically, using BU1's home range until late June 1999. During this period, we detected only 4 forays outside of BU1's $95 \%$ kernel: 1 to the northeast with other BU1 members, 1 brief excursion alone to the east, and 2 1-2 wk excursions alone into the areas used by MKA and MKB. (d) In June 1999, OG moved into the UC group when it was inside BU1's range, subsequently confining his movements to the UC group's range except for 1 excursion alone back into the BU1 range.

the area previously used by MKA (Fig. 6a, b). Except for a brief encounter $5 \mathrm{~d}$ later, the females in MKB never again associated with MKA females, and during August, the monthly centroid of their movements moved ca. $2 \mathrm{~km}$ to the northeast (Fig. 9). The 3 remaining MKA females continued to use their prior home range, while MKB females established a new, stable home range overlapping only slightly with that of MKA (Fig. 1). To our knowledge, no MKB female had prior experience in the new home range, but male OG had been sighted twice previously making solitary forays just outside the MKA range and into the area that MKB subsequently entered (Fig. 6a). 
Fig. 7 Centroid drift by males captured as adults. As measured by the locations of their monthly centroids, adult males moved on average $c a .400 \mathrm{~m}$ during the first month, then continued to drift farther from their initial locations by undertaking periodic secondary dispersal (mean $\pm \mathrm{SE}, N=21$ individuals whose radios operated for $\geq 2 \mathrm{yr}$ )

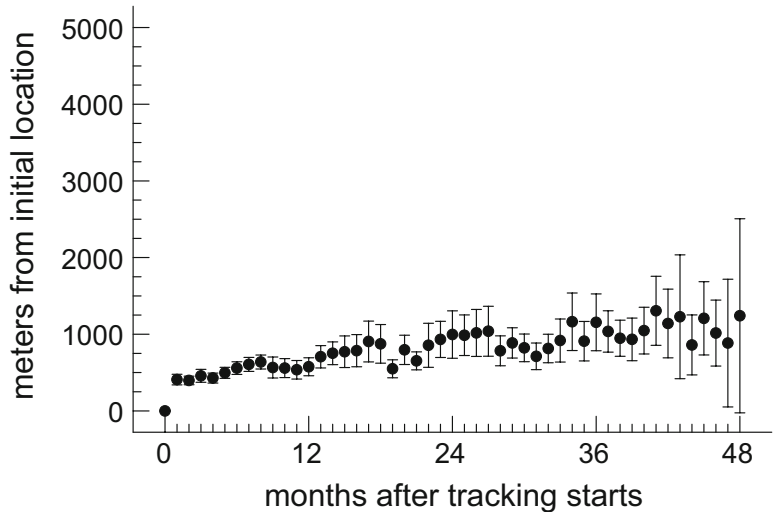

Individual Range Shifts by Females Associated with Abortive Group Fission

Unlike the other groups we followed, BU1 underwent several step changes in its home range between 1997 and 2006. This group (whose males were first collared in November 1996 but which was probably the same group followed by Olupot in 1992-1993) contained 7 females and 3 males in August 1997. Over the next 6 mo, it was joined by 6 new males, including 3 unmarked males that immigrated from

Fig. 8 Cases of secondary dispersal superimposed on a Google Earth image of Kibale Forest. Each line represents one case of dispersal. The gray lines are roads; forest borders visible in the image closely approximate the Kibale National Park boundaries. The abbreviation MUBFS indicates the location of the Makerere University Biological Field Station at Kanyawara; the name Ngogo locates the second major primate study site in Kibale (Mitani and Watts 2005).

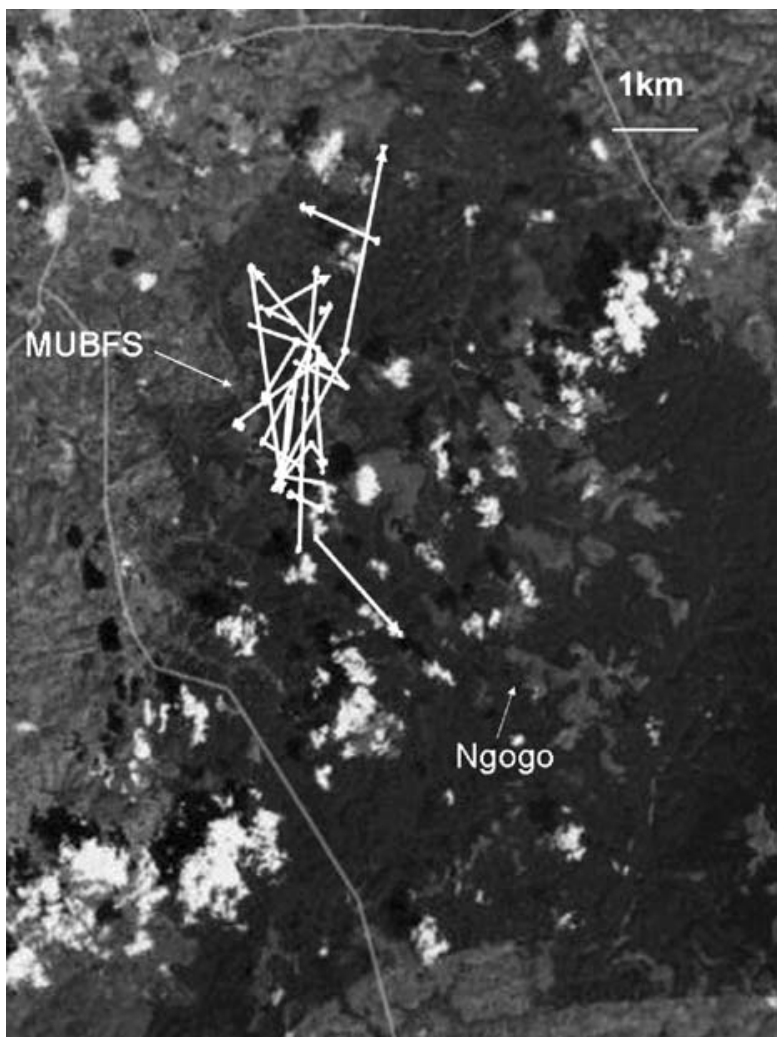


Fig. 9 Centroid movements of females associated with group fission. (Top) Monthly centroids for females in the MKA group remained 200-600 $\mathrm{m}$ from their initial locations during and after the spinoff of MKB females. In contrast, the group split coincided with a movement of ca. $2000 \mathrm{~m}$ by MKB females. (Bottom) Fission of the BU1 group illustrates another pattern: the entire group markedly shifted its range during mo 74 of the study, while fission did not occur until mo 80. After fission, BU1 returned to its earlier range, while BU2 drifted still farther away.
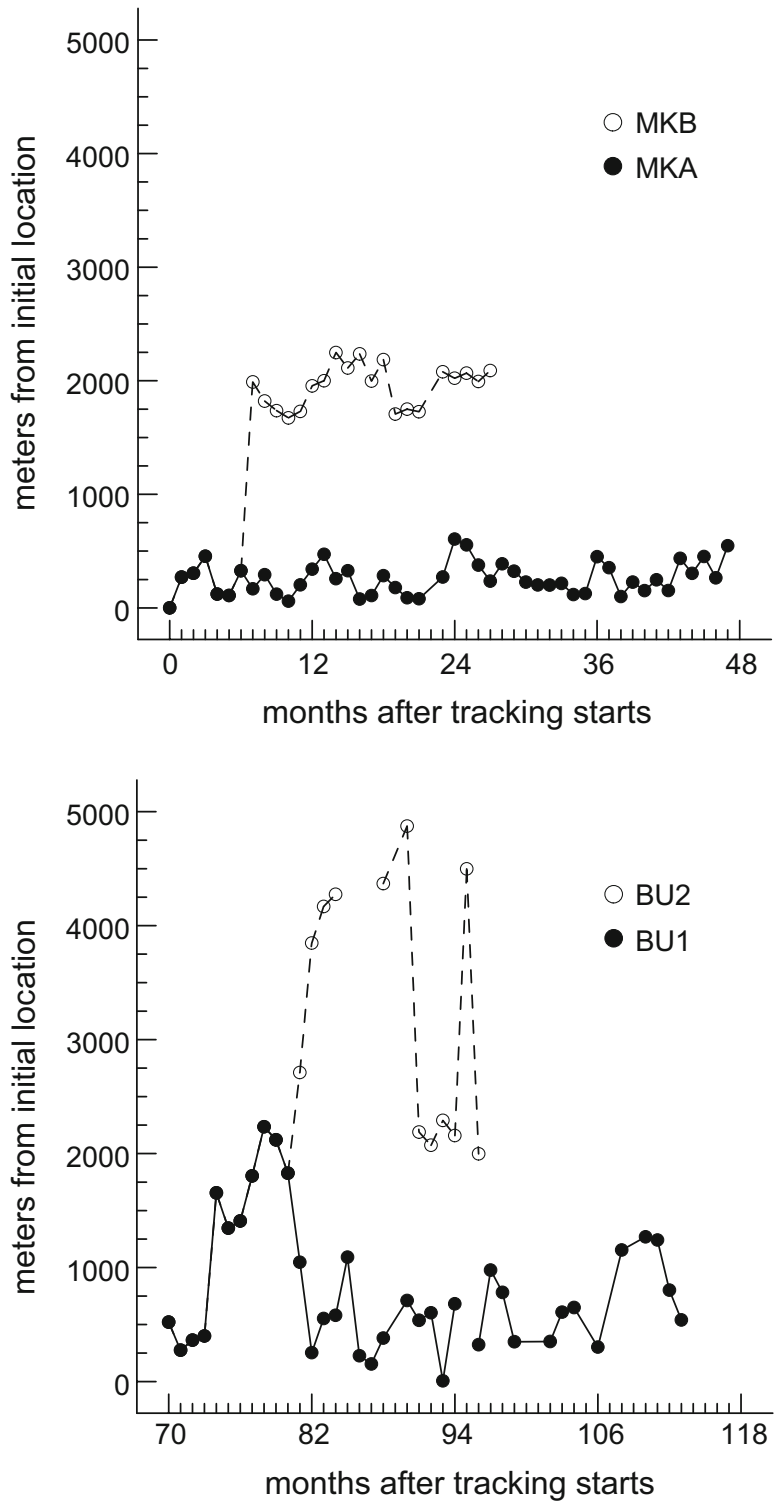

outside the study area in mid-January 1998. We subsequently collared 2 of these 3 males (RR and BB). Shortly thereafter, BU1 members began to split into temporary subgroups. We repeatedly noted parties of females foraging independently and separated by several hundred meters during January-March 1998, and the group began to expand its home range to the southwest.

On March 17, 1998, a subgroup containing 2 females, male RR and the unmarked immigrant male was sighted at the edge of the BU1 range, chased by BB and several other BU1 males. In response to repeated chases, these animals moved out of the forest, across several hundred meters of regenerating pine plantation into a completely 
new forest patch. What happened next resembled the fission of MKA in that members of BU1 moved rapidly into this new area. Within $2 \mathrm{wk}$, a subgroup led by BB was located $>1 \mathrm{~km}$ from the rest of the group and southwest of the former BU1 home range boundary. But unlike the MKA group, BU1 did not undergo a permanent split. Instead, all BU1 females and most males entered the new area. Throughout the following month, the group was split more often than not, and indeed periods of subgrouping alternated with periods of joint movement through the next 2 yr. But during this period, the BU1 centroid's location oscillated: in some months it was $\leq 100-200 \mathrm{~m}$ of its initial location, in others 700-900 m away. Both subgroups used the new area, and their composition was not stable, with both females and males moving between subgroups.

\section{Individual Range Shifts by Females Preceding Group Fission}

By 2003, BU1 was again moving as a single group, showing no signs of its 19982000 subgrouping. In April, the group contained 8 adult females and 2 adult males. But over the next $6 \mathrm{mo}$, an in- and outflow of 9 new males resulted in a substantial increase in fights and chases among males, and in the total number of males in the group. These trends paralleled those observed before BU1's home range shift in 1998, and they culminated in yet another shift (Fig. 10). On September 17, 2003, BU1 made a quantum move beyond the area it had previously used (Janmaat and Chancellor 2008). Over the next $7 \mathrm{mo}$, its centroid moved another kilometer to the south (1350-2250 $\mathrm{m}$ from its original location, Fig. 9).

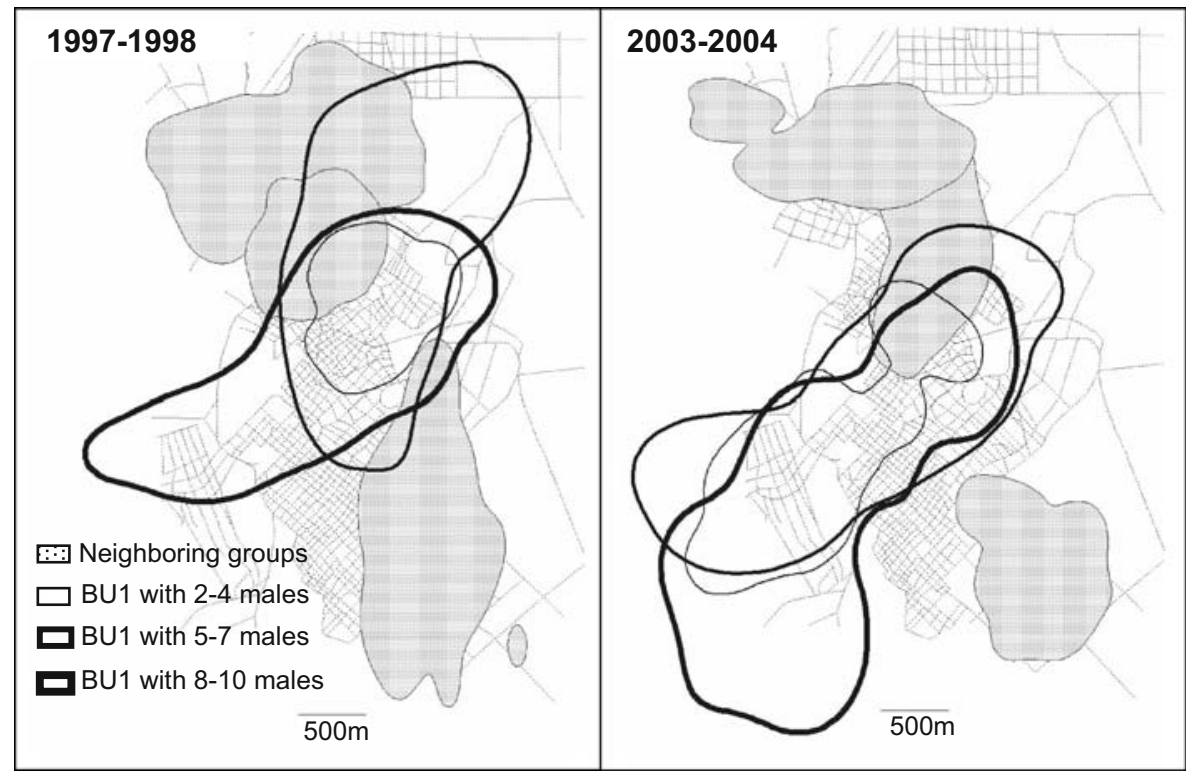

Fig. 10 Home range shifts of the BU1 group in 1997-1998 (associated with a temporary split) and 20032004 (followed by BU1's permanent fission). Each increment in the area that the group used was accompanied by an increase in the number of males in the group. 
The September home range shift was made by the entire BU1 group, but 3 mo later, females were again observed foraging in subgroups. Short-lived subgroups again formed in February 2004, and by April they were foraging independently for several days at a time. We observed both male and female transfers between subgroups until April 23, 2004, when the 2 subgroups split permanently. Each new group contained 4 adult females and 3-5 adult males. After the split, 1 subgroup returned to the earlier BU1 home range, while the other (BU2) foraged mostly within the new home range. In 2004-2005, the monthly centroids of BU2 female movements averaged $3350 \mathrm{~m}$ (range 2000-4900 m) from their initial location (Fig. 9).

\section{Discussion}

\section{Home Range Stability}

Whether we can define a mangabey's range as stable clearly depends on the time scale and the individuals studied. Over the short term — within a given yearmangabey social groups drift, presumably in response to temporary food abundance, as suggested originally by Waser $(1975,1976)$. However, when we compare home range boundaries in successive years they show much less drift and high year-to-year overlap. For 3 of our 4 focal groups, home ranges were highly stable over the entire 10 -yr period. Core areas were more labile, but group centroids drifted on the average only $530 \mathrm{~m}$ over the entire decade. This degree of home range stability is similar to or greater than that shown in the few comparable studies of other social mammals (Easley and Kinzey 1986; Jolly and Pride 1999; Young et al. 2006). The combination of short-term core area shifts but long-term home range stability is consistent with the possibility that, even though mangabeys may not visit particular areas for many months, they retain spatial information about those areas over the long term.

While most individuals spent years at a time within essentially constant areas, data from both radiotracked males and their social groups also revealed individual deviations from site fidelity. Deviations from site fidelity were associated directly or indirectly with dispersal or group fission. Surprisingly, when individuals did shift home ranges, most did so rapidly and seemingly without prior exploration. Radiocollared subadult males and a few adults extended their movements slowly into new areas through what appeared to be a gradual process of individual exploration. But most adult males did not venture outside familiar areas before the actual act of secondary dispersal, at which point they joined an adjacent group and thereafter moved within its previously unfamiliar home range. By familiar areas, we mean areas that the male had been known to use in his current or previous groups. It was striking that radiocollared males sometimes made solitary excursions outside their current group's home range, but only into areas they had been known to use earlier in their lives. The apparent willingness of radiocollared adult males to travel alone into areas they had used before, even into areas we had not seen them use for more than a year, contrasts with their lack of forays into unfamiliar areas until they actually joined a new group. 
Adult females, too, remained in familiar areas most of the time, but when they moved into new areas the shifts were discrete and substantial. Females in MKA and BU1 moved $\geq 1 \mathrm{~km}$ into novel areas on a time scale of a few days or a week before or during group fission. While we did detect movement of females between BU1 subgroups separated by $>1 \mathrm{~km}$, these movements occurred within BU1's previous home range; we never detected solitary females outside the home range of their group mates. Like males, females sometimes returned to previously used areas after very long periods of absence; most notably, BU1 females reverted to using much of their original range after spending 8 mo away from it (Fig. 9). These observations are consistent with the ideas that 1) familiarity is important and 2) on those rare occasions when adult mangabeys abandon familiar areas, they usually do so in a single step, and in the company of others.

A further unexpected aspect of individual home range shifts is that even while group home ranges remain stable, some females as well as males move impressive distances over their lifespans. We observed centroid movements approaching or exceeding $5 \mathrm{~km}$ by young males during natal dispersal, by adult males as a consequence of repeated secondary dispersal, and by adult females after group fission. While our observations confirm the common pattern that the average male moves farther during its lifetime than the average female, the magnitude of home range shifts by some mangabey females seems unusual. Remarkably few studies of mammalian group fission describe its effects on ranging patterns, focusing instead on social consequences (van Horn et al. 2007).

\section{Costs of Spatial Ignorance}

The pattern of home range stability found in the majority of our study groups makes sense when examined in terms of individuals: both adult males and females are conservative in their use of new areas as it is costly to move to new areas. Several studies demonstrate that spatial memory has adaptive value, e.g., birds (Shettleworth and Krebs 1982), mammals (Clarke et al. 1993), and fish (Markel 1994). Most of these studies show that predation risk increases in less familiar area as animals need longer time to find cover or escape routes compared to familiar area (prairie voles, Microtus ochrogaster: Jacquot and Solomon 1997; ruffed grouse, Bonasa umbellus: Yoder et al. 1976). Some studies suggest that animals suffer from a lower energetic efficiency due to the lack of memories of food or escape locations in the unfamiliar area. For example, Jacquot and Solomon (1997) showed that male prairie voles move farther and have trails that are more branched when placed experimentally in unfamiliar areas. For primates, Isbell et al. (1990) showed an increase in predation events in vervets when they entered an unfamiliar area.

Many of the large and preferred trees used by the Kibale mangabeys are Ficus trees that do not show clumped fruiting periods (Barrett and Lowen 1998; Waser 1975; Janmaat et al. 2006a). Trap lining is therefore unlikely to be an efficient fig finding strategy (Janson et al. 1986; Terborgh and Stern 1987). Recent studies suggest that the mangabeys indeed monitor individual Ficus trees (Janmaat et al. 2006a). The fruit productivity varies tremendously between individual trees. Phenological observations over a period of $16 \mathrm{yr}$ indicate that different trees initiated fruiting as few as 1 and as many as 28 times (Ficus sansibarica: $\min =4$, 
$\max =28, N=13$; Ficus exasperata: $\min =16, \max =24, N=14$; Ficus natalensis: $\min =1, \max =17, N=7$; Janmaat 2006; Wrangham and Chapman unpubl. data). Hence, mangabeys may especially benefit from long-term spatial knowledge because of the nature of food resources they favor. In fact, Janmaat and Chancellor (2008) showed that gray-cheeked mangabeys that enter an unfamiliar area suffer increased travel costs and decreased localization efficiency of Ficus fruit. In addition, their data suggest that mangabeys are less efficient in finding suitable routes for terrestrial travel and foraging in the unfamiliar area.

\section{Home Range Shifts During Male Dispersal}

Despite the costs of moving into unfamiliar areas, mangabey males did shift their range at least once a lifetime and often more. Dispersal is generally assumed to carry costs: Dispersing males have been reported to suffer higher predation risk (Alberts and Altmann 1995; Olupot and Waser 2001) and are assumed to risk starvation due to a lack of spatial knowledge of food sources (Boinski et al. 2005; Cheney and Seyfarth 1983).

To make up for its costs, dispersal is presumed to benefit the disperser by reducing inbreeding and mate competition. In primates, males frequently transfer into groups due to the presence of cycling females, e.g., mangabeys (Olupot and Waser 2001), baboons (Papio anubis: Packer 1979), langurs (Presbytis entellus: Borries 2000) or transfer into groups having more favorable sex ratios or fewer males than in their previous group (Jack and Fedigan 2004; Kuester and Paul 1999; Zhao 1994). Costs and benefits of primate dispersal have gained substantial attention, but few studies have been able to describe its spatial pattern. We found that young subadult males dispersed over many months and over distances of $\leq 5500 \mathrm{~m}$, crossing borders of $\leq 4$ home ranges. They traveled alone, interrupted by brief visits to and perhaps shadowing of social groups. While traversing unknown areas, young males presumably invested time and energy in the acquisition of spatial knowledge through individual search and memory. Dispersal by adult males, in contrast, typically lasted only a few days and occurred when old and new groups were traveling in overlapping areas. The majority of the adult males entered new areas only in the company of a group. When an adult male traveled alone, it was usually in areas that were already familiar to him.

Several models of animal dispersal predict that site fidelity should be positively related to age. Site fidelity should tend to increase with age as a result of a decrease in the potential number of future reproductive events available to compensate for the cost incurred (Morris 1982; Switzer 1993). Increasing site fidelity with age is also a common observation in field studies on birds (Newton 1993; Payne and Payne 1993). These studies suggest a tradeoff that limits the time that an animal can spend acquiring new spatial knowledge. Our observations of male mangabeys' individual range shifts raises an interesting possibility. Could it be that older males predominantly shift to groups that range in overlapping areas because they cannot afford to again invest in the acquisition of new knowledge? Given the high risk associated with solitary life (Olupot and Waser 2001), does it pay for them to enter new areas only when they are accompanied by more knowledgeable individuals such as a neighboring group? 
Unlike less gregarious taxa, primates rarely experience vacancies in neighboring home ranges after the death of a neighbor. Consequently, opportunities are rare to shift home ranges without risking conflict with neighboring groups. However, home range shifts where both males and females move into new areas together occur in a variety of primate species. Mountain gorillas (Gorilla gorilla) change their range every few years, resulting in high interannual overlap but low site fidelity over longer time periods (Watts 1998). In some cases, the overlap of a single group's range between years was lower than that between adjacent groups. Watts suggested that these changes in ranging area can be explained by the gorilla's dependence on terrestrial herbal vegetation, which regenerates slowly. Similar seminomadic behavior is reported for Angolan black-and-white colobines (Colobus angolensis ruwenzori; Fashing et al. 2007), snub-nosed monkeys (Rhinopithecus bieti: Kirckpatrick et al. 1998), and Japanese monkeys (Macaca fuscata: Watanuki et al. 1994). In these cases also, low site fidelity was suggested to result from slow regeneration of food resources: leaves, lichens, and dormancy buds of particular plant species, respectively.

For more fruit-dependent primates, we know of studies that report site infidelity only during the process of group fission (Cords and Rowell 1986; Struhsaker and Leland 1988; Windfelder and Lwanga 2002). Our study fits this pattern; mangabey females and their social groups shifted their range during temporary fission of BU1, 7 mo before a permanent group fission in BU1, and by daughter groups MKB and BU2 after permanent group fission.

The case study of BU1 is not unique among primates and resembles troop fissions associated with range shifts in olive baboons (Papio anubis: Nash 1976), rhesus monkeys (Macaca mulatta: Missakian 1973), Japanese macaques (M. fuscata: Furuya 1969), and toque macaques (M. sinica: Dittus 1988). Nash, Missakian, and Dittus all reported that the process of fission is long and can occur over 2-4 yr, and that groups shift their range before or after the final split. There are a number of other similarities between our observations in the BU1 group and other studies. Like Missakian (1973) and Dittus (1988), we recorded transfers of females between subgroups during the process of fission. As found by Nash (1976) and Furuya (1969), fissions and shifts coincided with periods when social relationships between males were unstable. Like Nash (1976), we found that instability coincided with the immigration of new males (Fig. 8).

\section{Are Individual Home Range Shifts Facilitated by a Finder-Joiner Mechanism?}

If long-term stability of group ranges reflects an advantage of grouping as a reservoir of spatial knowledge, then how do animals that undertake sudden home range shifts overcome the costs of entering an unfamiliar area? Do they simply enter new areas and use individual search-and-scan mechanisms to gradually find new food sources and safe routes for travel? Or could they follow knowledgeable individuals on their foraging routes, learning from them?

The second, perhaps less costly option, could be facilitated by a producerscrounger mechanism in which different individuals within a social group behave as 
finders or joiners (Bicca-Marques and Garber 2005; di Bitetti and Janson 2001; Giraldeau and Beauchamp 1999). By means of an experimental field study, BiccaMarques and Garber (2005) showed that $c a$. 50\% of the individuals in each study group initiated $\leq 90 \%$ of all food searches and acted as finders, while the rest, mostly dominant individuals, adopted a joiner strategy by monitoring the activities of others to obtain a reward. van Roosmalen (1988) reported that a male spider monkey (Ateles paniscus) visiting a fruiting tree on one day was followed by females to that tree on the next. In other words, joiners could benefit not only from direct searching activities of the finders but also from their spatial memory gained on previous foraging trips.

Our observations raise the possibility that adult male mangabeys use a finderjoiner mechanism when moving into new home ranges during secondary dispersal. Collared males did not explore their prospective group's home range during the months before joining it, but immediately adopted its home range afterwards. We postulate that such males profited from the spatial knowledge of their new group's adult females.

Similarly, during group fission and group home range shifts, females might learn new resource locations from recent male immigrants. Before the 1997 fission of MKA, we sighted male OG twice to the northeast of its normal home range; his subgroup later moved $>1 \mathrm{~km}$ into this area to become the new MKB group. Later in his life, OG made several excursions out of MKB's - and later out of BU1's home range - but never into areas he had not used in association with previous groups. Could his earlier excursions to the northeast of the MKA range indicate that he was already familiar with that area, and that he acted as a finder when he and the rest of the MKB group split off and moved there?

The home range shift of BU1 in 1998 was preceded by the immigration of 3 unmarked males; because Olupot had collared all males resident in the study area by that time, we can say with certainty that the new males did not originate from one of the neighboring groups to the north or east of BU1's home range. Hence, these males were likely to have come from the area to the southwest into which BU1 subsequently shifted. Similarly, BU1's shift still further south in 2004 was preceded by the immigration of a number of males that may have come from that direction. Arlet witnessed another influx resulting in a total of 9 adult males in the LC group in 2006; this influx also coincided with a brief exploration by LC of new areas within the MKA range (Fig. 1) and a temporary group split. Other studies of also reported the immigration of strange males before (Nash 1976) but more often after group fission (Macaca sylvanus: Ménard and Vallet, 1993; M. maurus: Okamoto and Matsumura 2001; Papio hamadryas: Hamilton and Bulger 1993; Cercopithecus ascanius: Struhsaker and Leland 1988; Windfelder and Lwanga 2002; C. mitis: Cords and Rowell 1986). In the rare cases wherein researchers have reported ranging data of the daughter groups, the group that had experienced a large influx of new males after fission was the one that moved into new areas (Struhsaker and Leland 1988, p. 385; Windfelder and Lwanga 2002), supporting the possibility that an influx of strangers also facilitates exploration of new areas in other primate species.

In the future, GPS collars and automated radiotracking will radically improve the precision and continuity of our knowledge of individual ranging patterns (Crofoot et al. 2008; Cushman et al. 2005; Patterson et al. 2007). We encourage others to 
exploit the opportunity that home range shifts associated with dispersal and group fission can provide to investigate the potential for social learning of spatial information.

Acknowledgments We thank Ken Glander for his help in developing the darting techniques, and Richard Kaserengenyu, John Rusoke, Clovice Kaganzi, Ramon Meijer, Luca Prevot, Duncan Wright, Peter Irumba, Charles Akora, Swaibu Katusabe, Richard Sabiiti, and John Koojo for invaluable assistance in the field. The Uganda National Council of Science and Technology approved the study. We also thank the Uganda Wildlife Authority, the Makerere University Biological Field Station, and the Kibale Fish and Monkey Project for logistic support and permission to conduct research in Kibale National Park. The Wenner-Gren and Leakey Foundations, the University of St Andrews' School of Psychology, the University of California Davis Department of Anthropology, the Schure-Bijerinck-Popping Foundation, the Stichting Kronendak, the Dobberke Stichting voor Vergelijkende Psychology, the Lucie Burger Stichting, the Foundation Doctor Catharine van Tussenbroek, the U.S. NIH/NIA, the National Geographic Society, the Wildlife Conservation Society, Primate Conservation International and the Rockefeller Foundation provided funding. Kerry Rabenold, Johel Chaves, and 2 anonymous reviewers provided helpful comments on early drafts of the manuscript.

Open Access This article is distributed under the terms of the Creative Commons Attribution Noncommercial License which permits any noncommercial use, distribution, and reproduction in any medium, provided the original author(s) and source are credited.

\section{References}

Alberts, S. C., \& Altmann, J. (1995). Balancing costs and opportunities: dispersal in male baboons. American Naturalist, 145, 279-306. doi:10.1086/285740.

Altmann, J., \& Alberts, S. C. (2003). Variability in reproductive success viewed from a life-history perspective in baboons. American Journal of Human Biology, 15, 401-409. doi:10.1002/ajhb.10157.

Baird, R. W., Gorgone, A. M., McSweeney, D. J., Webster, D. L., Salden, D. R., Deakos, M. H., et al. (2008). False killer whales (Pseudorca crassidens) around the main Hawaiian Islands: Long-term site fidelity, inter-island movements, and association patterns. Marine Mammal Science, 24(3), 591-612. doi:10.1111/j.1748-7692.2008.00200.x.

Barrett, L., \& Lowen, C. B. (1998). Random walks and the gas model: Spacing behaviour of gray-cheeked mangabeys. Functional Ecology, 12, 857-865. doi:10.1046/j.1365-2435.1998.00261.x.

Bicca-Marques, J. C., \& Garber, P. A. (2005). Use of social and ecological information in tamarin foraging decisions. International Journal of Primatology, 26, 1321-1344. doi:10.1007/s10764-005-8855-9.

Boinski, S., Kauffman, L., Ehmke, E., Schet, S., \& Vreedzaam, A. (2005). Dispersal patterns among three species of squirrel monkeys (Saimiri oerstedii, S. boliviensis and S. sciureus): divergent costs and benefits. Behaviour, 142, 525-632. doi:10.1163/1568539054352888.

Borries, C. (2000). Male dispersal and mating season influxes in Hanuman langurs living in multi-male groups. In P. M. Kappeler (Ed.), Primate males: Causes and consequences of variation in group composition (pp. 146-158). Cambridge, UK: Cambridge University Press.

Bronikowski, M., \& Altmann, J. (1996). Foraging in a variable environment: weather patterns and the behavioral ecology of baboons. Behavioral Ecology and Sociobiology, 39, 11-25. doi:10.1007/ s002650050262.

Chancellor, R. L., \& Isbell, L. A. (2008). Female grooming markets in a population of gray-cheeked mangabeys. Behavioral Ecology, 20, 79-86. doi:10.1093/beheco/arn117.

Chapman, C. A., Chapman, L. J., Wrangham, R., Isabirye-Basuta, G., \& Ben-David, K. (1997). Spatial and temporal variability in the structure of a tropical forest. African Journal of Ecology, 35, 341-436. doi:10.1111/j.1365-2028.1997.083-89083.x.

Chapman, C. A., Wrangham, R. W., Chapman, L. J., Kennard, D. K., \& Zanne, A. E. (1999). Fruit and flower phenology at two sites in Kibale National Park, Uganda. Journal of Tropical Ecology, 15, 189211. doi:10.1017/S0266467499000759.

Cheney, D. L., \& Seyfarth, R. M. (1983). Nonrandom dispersal in free ranging vervet monkeys: Social and genetic consequences. American Naturalist, 122, 392-412. doi:10.1086/284142. 
Chepko-Sade, B. D., \& Sade, D. S. (1979). Patterns of group splitting within matrilineal kinship groups: A study of social group structure in Macaca mulatta (Cercopithecine: Primates). Behavioral Ecology and Sociobiology, 5, 67-87. doi:10.1007/BF00302696.

Clarke, M. F., Burke da Silva, K., Lair, H., Pocklington, R., Kramer, D. L., \& McLaughlin, R. L. (1993). Site familiarity affects escape behaviour of the eastern chipmunk Tamias striatus. Oikos, 66, 533-537. doi: $10.2307 / 3544949$.

Cords, M., \& Rowell, T. E. (1986). Group fission in blue monkeys of the Kakamega Forest, Kenya. Folia Primatologica, 46, 70-82. doi:10.1159/000156239.

Crofoot, M. C., Gilby, I. C., Wikelski, M. C., \& Kays, R. W. (2008). Interaction location outweighs the competitive advantage of numerical superiority in Cebus capucinus intergroup contests. Proceedings of the National Academy of Sciences of the United States of America, 105, 577-581. doi:10.1073/ pnas.0707749105.

Cushman, S. A., Chase, M., \& Griffin, C. (2005). Elephants in space and time. Oikos, 109, 331-341. doi:10.1111/j.0030-1299.2005.13538.x.

di Bitetti, M. S., \& Janson, C. H. (2001). Social foraging and the finder's share in capuchin monkeys, Cebus apella. Animal Behaviour, 62, 47-56. doi:10.1006/anbe.2000.1730.

di Fiore, A., \& Suarez, S. A. (2007). Route-based travel and shared routes in sympatric spider and woolly monkeys: Cognitive and evolutionary implications. Animal Cognition, 10, 317-329. doi:10.1007/ s10071-006-0067-y.

Dittus, W. P. J. (1988). Group fission among wild toque macaques as a consequence of female resource competition and environmental stress. Animal Behaviour, 36, 1626-1645. doi:10.1016/S0003-3472 (88)80104-0.

Easley, S. P., \& Kinzey, W. G. (1986). Territorial shift in the yellow-handed titi monkey (Callicebus torquatus). American Journal of Primatology, 11, 307-318. doi:10.1002/ajp.1350110402.

Fashing, P. J., Mulindahabi, F., Gakima, J., Masozera, M., Mununura, I., Plumptre, A. J., et al. (2007). Activity and ranging patterns of Colobus angolensis ruwenzori in Nyungwe forest, Rwanda: Possible costs of large group size. International Journal of Primatology, 28, 529-550. doi:10.1007/s10764006-9095-3.

Fieberg, J., \& Kochanny, C. (2005). Quantification of home range overlap: The importance of the utilization distribution. The Journal of Wildlife Management, 69, 1346-1359. doi:10.2193/0022-541X (2005)69[1346:QHOTIO]2.0.CO;2.

Furuya, Y. (1969). On the fission of troops of Japanese monkeys. Primates, 10, 47-69. doi:10.1007/ BF01730809.

Gamble, L. R., McGarigal, K., \& Compton, B. W. (2007). Fidelity and dispersal in the pond-breeding amphibian, Ambystoma opacum: Implications for spatio-temporal population dynamics and conservation. Biological Conservation, 139, 247-257. doi:10.1016/j.biocon.2007.07.001.

Giraldeau, L. A., \& Beauchamp, G. (1999). Food exploitation: Searching for the optimal joining policy. Trends in Ecology \& Evolution, 14, 102-106. doi:10.1016/S0169-5347(98)01542-0.

Hamilton, W. J., \& Bulger, J. (1993). Origin and fate of a one-male savanna baboon group formed by fissioning. International Journal of Primatology, 14, 131-143. doi:10.1007/BF02196508.

Hutchinson, J. M. C., \& Waser, P. M. (2007). Use, misuse and extensions of "ideal gas" models of animal encounter. Biological Reviews of the Cambridge Philosophical Society, 82, 335-359. doi:10.1111/ j.1469-185X.2007.00014.x.

Isbell, L. A., Cheney, D. L., \& Seyfarth, R. M. (1990). Costs and benefits of home range shifts among vervet monkeys (Cercopithecus aethiops) in Amboseli National Park, Kenya. Behavioral Ecology and Sociobiology, 27, 351-358. doi:10.1007/BF00164006.

Jack, K. M., \& Fedigan, L. (2004). Male dispersal patterns in white-faced capuchins, Cebus capucinus. Part 2: Patterns and causes of secondary dispersal. Animal Behaviour, 67, 771-782. doi:10.1016/j. anbehav.2003.06.015.

Jacquot, J., \& Solomon, N. G. (1997). Effects of site familiarity on movement patterns of male prairie voles Microtus ochrogaster. American Midland Naturalist, 138, 414-417. doi:10.2307/2426834.

Janmaat, K. R. L. (2006). Fruits of enlightenment. Fruit localization strategies in wild mangabey monkeys. Ph.D. thesis, University of St. Andrews, St. Andrews.

Janmaat, K. R. L., \& Chancellor, R. (2008) Moving into less familiar areas: The importance of long-term spatial memory for mangabey foraging efficiency. 21 st Conference of the International Primatological Society, June 25-30, Edinburgh, UK.

Janmaat, K. R. L., Byrne, R. W., \& Zuberbühler, K. (2006a). Evidence for spatial memory of fruiting states of rain forest fruit in wild ranging mangabeys. Animal Behaviour, 71, 797-807. doi:10.1016/j. anbehav.2005.12.009. 
Janmaat, K. R. L., Byrne, R. W., \& Zuberbühler, K. (2006b). Primates take weather into account when searching for fruit. Current Biology, 16, 1232-1237. doi:10.1016/j.cub.2006.04.031.

Janson, C. H., Stiles, E. W., \& White, D. W. (1986). Selection on plant fruiting traits by brown capuchin monkeys: A multivariate approach. In A. Estrada, \& T. Fleming (Eds.), Frugivores and seed dispersal (pp. 83-92). The Hague: Junk.

Jolly, A., \& Pride, E. (1999). Troop histories and range inertia of Lemur catta at Berenty, Madagascar: A 33-year perspective. International Journal of Primatology, 20, 359-373. doi:10.1023/A: 1020548620372.

Kernohan, B. J., Gitzen, R. A., \& Millspaugh, J. J. (2001). Analysis of animal space use and movements. In J. J. Millspaugh, \& J. M. Marzluff (Eds.), Radiotracking animal populations (pp. 125-166). San Diego: Academic Press.

Kirkpatrick, R. C., Long, Y. C., Zhong, T., \& Xiao, L. (1998). Social organization and range use in the Yunnan snub-nosed monkey Rhinopithecus bieti. International Journal of Primatology, 19, 13-50. doi:10.1023/A:1020302809584.

Krebs, J. R. (1970). Territory and breeding density in the great tit. Parus major L. Ecology, 52, 1-22.

Kuester, J., \& Paul, A. (1999). Male migration in Barbary macaques (Macaca sylvanus) at Affenberg Salem. International Journal of Primatology, 20, 85-106. doi:10.1023/A:1020536317646.

Markel, R. W. (1994). An adaptive value of spatial learning and memory in blackeye goby, Goryphopoterus nicholsi. Animal Behaviour, 47, 1462-1464. doi:10.1006/anbe.1994.1194.

Ménard, N., \& Vallet, D. (1993). Dynamics of fission in a wild Barbary macaque group (Macaca sylvanus). International Journal of Primatology, 14, 479-500. doi:10.1007/BF02192778.

Mertl-Millhollen, A. S. (2000). Tradition in Lemur catta behavior at Berenty Reserve, Madagascar. International Journal of Primatology, 21(2), 287-297. doi:10.1023/A:1005429621566.

Minta, S. C. (1992). Tests of spatial and temporal interaction among animals. Ecological Applications, 2, 178-188. doi:10.2307/1941774.

Missakian, E. A. (1973). The timing of fission among free-ranging rhesus monkeys. American Journal of Physical Anthropology, 38, 621-624. doi:10.1002/ajpa.1330380277.

Mitani, J. C., \& Watts, D. P. (2005). Correlates of territorial boundary patrol behaviour in wild chimpanzees. Animal Behaviour, 70, 1079-1086. doi:10.1016/j.anbehav.2005.02.012.

Mitchell, B. R. (2006). Comparison of programs for fixed kernel home range analysis. http://www. wildlife.org/wg/gis/newsletter/jun06/hrcompar.htm.

Morris, D. W. (1982). Age specific dispersal strategies in iteroparous species: Who leaves when? Evolutionary Theory, 6, 53-65.

Murray, C. M., Gilby, I. C., Mane, S. V., \& Pusey, A. E. (2008). Adult male chimpanzees inherit maternal ranging patterns. Current Biology, 18, 20-24. doi:10.1016/j.cub.2007.11.044.

Nash, L. T. (1976). Troop fission in free ranging baboons in the Gombe Stream National Park, Tanzania. American Journal of Physical Anthropology, 44, 63-78. doi:10.1002/ajpa.1330440109.

Newton, I. (1993). Age and site fidelity in female sparrowhawks, Accipiter nisus. Animal Behaviour, 46, 161-168. doi:10.1006/anbe.1993.1171.

Okamoto, K., \& Matsumura, S. (2001). Group fission in moor macaques (Macaca maurus). International Journal of Primatology, 22, 481-493. doi:10.1023/A:1010711813637.

Olupot, W. (1998). Long-term variation in mangabey (Cercocebus albigena johnstoni Lydekker) feeding in Kibale National Park, Uganda. African Journal of Ecology, 36, 96-101. doi:10.1046/j.13652028.1998.110-89110.x.

Olupot, W. (2000a). Darting, individual recognition and radiotracking in grey-cheeked mangabeys, Lophocebus albigena in Kibale National park. African Primates, 4, 40-49.

Olupot, W. (2000b). Body mass differences among male mangabeys inhabiting logged and unlogged forest compartments. Conservation Biology, 14, 833-843. doi:10.1046/j.1523-1739.2000. 98585.x.

Olupot, W., Chapman, C. A., Brown, C. H., \& Waser, P. M. (1994). Mangabey (Cercocebus albigena) population density, group size and ranging: A twenty year comparison. American Journal of Primatology, 32, 197-205. doi:10.1002/ajp.1350320306.

Olupot, W., \& Waser, P. M. (2001). Activity patterns, habitat use and mortality risks of mangabey males living outside social groups. Animal Behaviour, 61, 1227-1235. doi:10.1006/anbe.2000.1709.

Olupot, W., \& Waser, P. M. (2005). Patterns of male residency and intergroup transfer in gray-cheeked mangabeys (Lophocebus albigena). American Journal of Primatology, 66, 331-349. doi:10.1002/ ajp. 20160 .

Packer, C. (1979). Intertroop transfer and inbreeding avoidance in Papio anubis. Animal Behaviour, 27, 136. doi:10.1016/0003-3472(79)90126-X. 
Patterson, T. A., Thomas, L., Wilcox, C., Ovaskainen, O., \& Mattiopoulos, J. (2007). State-space models of individual animal movement. Trends in Ecology \& Evolution, 23, 87-94. doi:10.1016/j.tree.2007.10.009.

Payne, R. B., \& Payne, L. L. (1993). Breeding dispersal in indigo buntings: Circumstances and consequences for breeding success and population structure. The Condor, 95, 1-24. doi:10.2307/1369382.

Poirier, F. E. (1968). Analysis of a Nilgiri langur (Presbytis johnii) home range change. Primates, 9, 2943. doi:10.1007/BF01795884.

Pontzer, H., \& Houle, A. (2005). Kibale National Park ArcView CD. Harvard University.

Powell, R. A. (2000). Animal home ranges and territories and home range estimators. In L. Bortani, \& T. K. Fuller (Eds.), Research techniques in animal ecology (pp. 65-110). New York: Columbia University Press.

Rodgers, A. R., Carr, A. P., Beyer, H. L., Smith, L., \& Kie, J. G. (2007). HRT: Home range tools for ArcGIS. version 1.1. Ontario Ministry of Natural Resources, Centre for Northern Forest Ecosystem Research, Thunder Bay, Ontario.

Schjorring, S., Gregersen, J., \& Bregnballe, T. (2000). Sex difference in criteria determining fidelity towards breeding sites in the great cormorant. Journal of Animal Ecology, 69, 214-223. doi:10.1046/ j.1365-2656.2000.00385.x.

Seaman, D. E., Millspaugh, J. J., Kernohan, B. J., Brundige, G. C., Raedeke, K. J., \& Gitzen, R. A. (1999). Effects of sample size on kernel home range estimates. The Journal of Wildlife Management, 63, 739-747. doi:10.2307/3802664.

Shettleworth, S. J., \& Krebs, J. R. (1982). How marsh tits find their hoards: The roles of site preference and spatial memory. Journal of Experimental Psychology, 8, 354-375.

Singleton, I., \& van Schaik, C. P. (2001). Orangutan home range size and its determinants in a Sumatran swamp forest. International Journal of Primatology, 22, 877-911. doi:10.1023/A:1012033919441.

Struhsaker, T. T. (1997). Ecology of an African rainforest. Gainesville: University Press of Florida.

Struhsaker, T. T., \& Leland, L. (1988). Group fission in redtail monkeys (Cercopithecus ascanius) in the Kibale forest, Uganda. In A. Gautier-Hion, F. Bourlière, J.-P. Gautier, \& J. Kingdon (Eds.), A primate radiation: Evolutionary biology of the African guenons (pp. 364-388). New York: Cambridge University Press.

Sugiyama, Y. (1960). On the division of a natural troop of Japanese monkeys at Takasakiyama. Primates, 2, 109-148. doi:10.1007/BF01659166.

Switzer, P. V. (1993). Site fidelity in predictable and unpredictable habitats. Evolutionary Ecology, 7, 533555. doi:10.1007/BF01237820.

Switzer, P. V. (1997). Factors affecting site fidelity in a territorial animal, Perithemis tenara. Animal Behaviour, 53, 865-877. doi:10.1006/anbe.1996.0352.

Terborgh, J., \& Stern, M. (1987). The surreptitious life of the saddle-backed tamarin. American Scientist, 75, 260-269.

van Horn, R. C., Buchan, J. C., Altmann, J., \& Alberts, S. C. (2007). Divided destinies: Group choice by female savannah baboons during social group fission. Behavioral Ecology and Sociobiology, 61, 1823-1837. doi:10.1007/s00265-007-0415-1.

van Noordwijk, M. A., \& van Schaik, C. P. (2001). Career moves: Transfer and rank challenge decisions by male long-tailed macaques. Behaviour, 138, 359-395. doi:10.1163/15685390152032505.

van Roosmalen, M. G. M. (1988). Diet, feeding behaviour and social organization of the Guianan black spider monkey (Ateles paniscus paniscus). In 12th Congress of the International Primatological Society, July 24-29, Brasilia, Brazil.

Waser, P. M. (1975). Monthly variations in feeding and activity patterns of the mangabey, Cercocebus albigena (Lydekker). E. African Wildlife Journal, 13, 249-263.

Waser, P. M. (1976). Cercocebus albigena: Site attachment, avoidance, and intergroup spacing. American Naturalist, 11, 911-933.

Waser, P. M. (1977). Individual recognition, intragroup cohesion, and intergroup spacing: Evidence for sound playback to forest monkeys. Behaviour, 60, 28-74. doi:10.1163/156853977X00270.

Waser, P. M. (1985). Spatial structure in mangabey groups. International Journal of Primatology, 6, 569580. doi:10.1007/BF02692289.

Watanuki, Y., Nakayama, Y., Azuma, S., \& Ashizawa, S. (1994). Foraging on buds and bark of mulberry trees by Japanese monkeys and their range utilization. Primates, 35, 15-24. doi:10.1007/BF02381482.

Watts, D. P. (1998). Long-term habitat use by mountain gorillas (Gorilla gorilla beringei). 1. Consistency, variation, and home range size and stability. International Journal of Primatology, 19, 651-679. doi:10.1023/A:1020324909101.

Wauters, L. A., Lens, L., \& Dhondt, A. A. (1995). Variation in territory fidelity and territory shifts among red squirrel, Sciurus vulgaris, females. Animal Behaviour, 49, 187-193. doi:10.1016/0003-3472(95)80166-9. 
Webb, J. K., \& Shine, R. (1997). A field study of spatial ecology and movements of a threatened snake species, Hoplocephalus bungaroides. Biological Conservation, 82, 203-217. doi:10.1016/S00063207(97)00032-3.

Windfelder, T. L., \& Lwanga, J. S. (2002). Group fission in red-tailed monkeys (Cercopithecus ascanius) in Kibale National Park, Uganda. In M. Cords, \& M. E. Glenn (Eds.), The guenons: Diversity and adaptation in African monkeys (pp. 147-159). New York: Kluwer Academic.

Yoder, J. M., Marschall, E. A., \& Swanson, D. A. (1976). The cost of dispersal: Predation as a function of movement and site familiarity in ruffed grouse. Behavioral Ecology, 15, 469-476. doi:10.1093/ beheco/arh037.

Young, J. K., Andelt, W. F., Terletzky, P. A., \& Shivik, J. A. (2006). A comparison of coyote ecology after 25 years: 1978 versus 2003. Canadian Journal of Zoology, 84, 573-582. doi:10.1139/Z06-030.

Zhao, Q. (1994). Mating competition and intergroup transfer of males in Tibetan macaques (Macaca thibetana) at Mt. Emei, China. Primates, 35, 57-68. doi:10.1007/BF02381486. 